\title{
A Dose-Ranging Study of the Novel Inhaled Dual PDE 3 and 4 Inhibitor Ensifentrine in Patients with COPD Receiving Maintenance Tiotropium Therapy
}

\author{
Gary T Ferguson' \\ Edward M Kerwin $\mathbb{D}^{2}$ \\ Tara Rheault ${ }^{3}$ \\ Thomas Bengtsson ${ }^{4}$ \\ Kathleen Rickard $\mathbb{D D}^{3}$ \\ 'Pulmonary Research Institute of \\ Southeast Michigan, Farmington Hills, MI, \\ USA; ${ }^{2}$ Altitude Clinical Consulting, \\ Medford, OR, USA; ${ }^{3}$ Verona Pharma, Plc, \\ Raleigh, NC, USA; ${ }^{4}$ Stat Mind AB, Lund, \\ Sweden
}

Correspondence: Tara Rheault Verona Pharma, 8045 Arco Corporate Drive, Suite 130, Raleigh, NC, 27617, USA

Tel + 646-530-2I26

Email tara.rheault@veronapharma.com
Purpose: Ensifentrine is an inhaled dual inhibitor of phosphodiesterase (PDE) 3 and 4 that has shown bronchodilatory effects and symptom improvement in clinical studies in patients with chronic obstructive pulmonary disease (COPD), and anti-inflammatory effects in healthy volunteers in a model of COPD-like inflammation. This manuscript reports on the results of the clinical study examining if ensifentrine provides meaningful improvements in lung function when added on to tiotropium over 4 weeks in patients with COPD who have impaired lung function and symptoms despite treatment with tiotropium.

Patients and Methods: This randomized, double-blind, placebo-controlled, parallel-group, dose-ranging study recruited patients with moderate-to-severe COPD. Patients were randomized to open-label tiotropium once daily (QD) plus $(+)$ blinded escalating doses of ensifentrine or placebo twice daily (BID). Effects on lung function, symptoms and quality of life (QoL) were assessed over 4 weeks.

Results: A total of 416 COPD patients were randomized and 413 received at least one dose of blinded study medication + tiotropium. All ensifentrine doses produced a significant and dose-dependent increase in peak forced expiratory volume in 1 second (FEV1) from baseline to Week 4, with placebo-corrected differences of $77.5 \mathrm{~mL}$ when added to tiotropium (0.375 mg; 95\% CI: 4.8, $150.1 \mathrm{~mL} ; \mathrm{p}=0.037)$ to $124.2 \mathrm{~mL}(3 \mathrm{mg} ; 95 \% \mathrm{CI}: 51.0$, $196.8 \mathrm{~mL} ; \mathrm{p}<0.001)$. A significant increase in average FEV1 $(0-12 \mathrm{~h})$ was shown at Week 4 with the $3 \mathrm{mg}$ dose $(87.3 \mathrm{~mL}$; $95 \% \mathrm{CI}: 20.0,154.5 \mathrm{~mL}$; $\mathrm{p}=0.011)$. Clinically meaningful and statistically significant improvements in the St. George's Respiratory Questionnaire COPD (SGRQ-C) additive to tiotropium were observed at Week 4, exceeding the minimally clinically important difference of 4 units with the 1.5 and $3 \mathrm{mg}$ doses. Adverse events were similar in frequency between the ensifentrine and placebo arms.

Conclusion: This clinical study demonstrated that nebulized ensifentrine added on to tiotropium produced clinically important improvements in lung function and QoL over 4 weeks in COPD patients receiving tiotropium who demonstrated symptoms and lung function impairment, with a safety profile similar to placebo.

Keywords: dual PDE3 and 4 inhibitor, phosphodiesterase, COPD, tiotropium, bronchodilation

\section{Plain Language Summary}

This study evaluated if nebulized ensifentrine provides additional improvements in lung function when added to tiotropium in COPD patients who have impaired lung function and symptoms despite treatment with tiotropium. Study results showed that, when added to tiotropium, ensifentrine produced clinically meaningful and statistically significant 
bronchodilation with a dose-dependent increase from baseline to peak FEV1 after 4 weeks. Interpretation: When nebulized ensifentrine was added on to tiotropium maintenance therapy, it produced dose-dependent, clinically important improvements in lung function over 4 weeks in COPD patients receiving tiotropium who demonstrated symptoms and lung function impairment.

\section{Introduction}

The World Health Organization listed chronic obstructive pulmonary disease (COPD) as the third leading cause of death worldwide in 2019. ${ }^{1}$ COPD is characterized by chronic, irreversible airflow obstruction and persistent airway inflammation leading to symptoms such as dyspnea, cough and sputum production and resulting in a reduced quality of life (QoL). ${ }^{2}$ Current standard of care, including treatment with inhaled long-acting bronchodilators and corticosteroids, has been shown to improve lung function, COPD symptoms and healthrelated QoL and to reduce exacerbation frequency. However, even with maximal inhaled therapies, many patients remain symptomatic and functionally impaired. $^{2-4}$ Thus, new treatment options are urgently needed for patients with COPD which can provide additional bronchodilation and anti-inflammatory effects targeting the chronic inflammatory pathology associated with COPD.

Phosphodiesterases (PDEs) are enzymes that impact a range of cellular functions by modulating intracellular levels of cyclic nucleotide signaling molecules. PDE3 regulates cyclic adenosine monophosphate (cAMP) and cyclic guanosine monophosphate (cGMP) concentrations in airway smooth muscle, such that inhibition results in airway smooth muscle relaxation. ${ }^{5-7}$ PDE4 regulates cAMP concentrations and is involved in inflammatory cell activation; consequently, inhibition has anti-inflammatory effects. ${ }^{8-10}$ There is evidence to suggest that combined inhibition of PDE3 and PDE4 may have additive or synergistic effects with respect to both anti-inflammatory and bronchodilator activity given the expression of both PDE isoforms on inflammatory cells and airway smooth muscles, respectively. ${ }^{11}$

Ensifentrine is a first-in-class inhaled dual inhibitor of PDE3 and 4. In a 4-week study, nebulized ensifentrine alone demonstrated significant bronchodilatory effects and symptom improvement and was well tolerated, with an adverse event profile similar to placebo, in COPD patients at doses from 0.75 to $6 \mathrm{mg}$ twice daily. ${ }^{12}$ When added on to standard classes of bronchodilators in short-term studies in patients with COPD, ensifentrine showed rapid and meaningful improvement in lung function and a reduction in lung volumes, which may indicate an effect on small airways and a physiological mechanism for symptom relief. ${ }^{13}$ Antiinflammatory effects including a significant reduction in inflammatory cell types (ie, macrophages, neutrophils, lymphocytes and eosinophils) were demonstrated in the sputum of healthy volunteers challenged with the antigen lipopolysaccharide (a model of COPD-like inflammation) after 6-days of dosing with ensifentrine. ${ }^{14}$

This Phase IIb study examined the efficacy and safety of nebulized ensifentrine in doses ranging from 0.375 to $3 \mathrm{mg}$ twice daily (BID) added to a once-daily (QD) longacting muscarinic antagonist (LAMA; tiotropium) over 4 weeks and in patients with COPD who continued to have impaired lung function and significant dyspnea following a 2-week run-in on tiotropium.

\section{Patients and Methods}

Tiotropium (delivered via Spiriva ${ }^{\circledR}$ Respimat $^{\circledR}$, two puffs $2.5 \mu \mathrm{g}$ QD) was selected as a commonly prescribed LAMA bronchodilator to provide a uniform background maintenance treatment for all patients across the run-in and treatment periods. LAMAs are a recommended treatment for symptomatic COPD patients. ${ }^{2}$ Symptomatic patients with a pre-dose FEV1 of $30-70 \%$ and a modified Medical Research Council (mMRC) dyspnea scale score $\geq 2$ after 2 weeks of daily treatment with tiotropium were selected to examine the benefits of added nebulized ensifentrine in this population. The study was approved by independent ethics committees at each institution and was performed in accordance with the Declaration of Helsinki and Good Clinical Practice (ICH/CPMP/135/95). Written informed consent was obtained from all patients. The study is registered at ClinicalTrials.gov (NCT03937479). All participating sites used Copernicus Group Independent Review Board (CGIRB) of Cary, NC, USA.

\section{Design}

This was a randomized, double-blind, placebo-controlled, 5-arm parallel group study examining the dose-dependent effects of nebulized ensifentrine BID on lung function in patients with moderate-to-severe COPD. Eligible patients at screening entered a 2-week run-in period with openlabel tiotropium. All patients received short-acting bronchodilators (albuterol metered dose inhaler) for rescue use that was withheld at least 6 hours prior to spirometry. 
Following the run-in period, patients demonstrated predose forced expiratory volume in 1 second (FEV1) of $30-70 \%$ predicted and $\geq 2$ on the mMRC dyspnea scale for randomization eligibility. Patients were stratified at entry based on V1 reversibility status following treatment with albuterol ("reversible": $\geq 12 \%$ and $\geq 200 \mathrm{~mL}$ increase in FEV1; or "non-reversible": $<12 \%$ or $<200 \mathrm{~mL}$ increase in FEV1; each stratum capped at 50\%) and randomized equally to receive double-blinded nebulized study medication BID added to open-label tiotropium QD for 4 weeks.

Patients were 40-80 years old, and had baseline postbronchodilator (four puffs of albuterol) FEV1/FVC ratio of $\leq 0.70$ and FEV $1 \geq 30 \%$ and $\leq 70 \%$ of predicted normal (NHANES III) after meeting a 48-hour washout of any background maintenance bronchodilators, a score of $\geq 2$ on the mMRC dyspnea scale, and current or former smoking status with smoking history of $\geq 10$ pack years. Patients with a history of asthma or other pulmonary disease; oral COPD therapy within 3 months (eg, oral steroids, theophylline, and roflumilast), inhaled corticosteroids (ICS) therapy within 4 weeks or a history of any COPD exacerbation requiring treatment with systemic corticosteroids or antibiotics within 3 months, or a severe COPD exacerbation within 6 months of screening were excluded. The Supplementary Materials display the complete study design (Supplement Figure 1), eligibility and randomization criteria (Supplement Tables 1-3), and study procedures (Supplement Table 4).

At randomization, baseline (pre-study medication dose) data were collected for spirometry (FEV1), St. George's Respiratory Questionnaire - COPD (SGRQ-C), Baseline Dyspnea Index (BDI), electrocardiogram (ECG) and vital signs (eg, blood pressure, pulse rate). All baseline measurements were assessed with patients on steady state tiotropium at the morning trough (pre-dose), including spirometry. Patients were administered tiotropium in the clinic followed by double-blind nebulized study medication after completion of pre-dose assessments. Spirometry was assessed pre-dose at -30 minutes (min) and up to 3 hours (h) post-dose (+30min, 1, 2, and 3h) on Weeks 1, 2 and 3, and up to $12 \mathrm{~h}$ post-dose (+30min, 1, 2, 3, 4, 6, 8 and 12h) on Day 1 and Week 4. Transition Dyspnea Index (TDI) and SGRQ-C, were assessed pre-dose at Weeks 2 and 4. Daily throughout the study (including run-in) patients used an e-diary to record rescue medication use and COPD symptoms (Evaluating Respiratory Symptoms [E-RS ${ }^{\text {TM: }}$ COPD] questionnaire). Permissions were obtained for the use of the instruments. Vital signs and 12- lead ECGs were assessed pre- and post-dose on all visits. Adverse events (AEs) were captured over the study duration.

\section{Outcomes}

\section{Efficacy}

The primary endpoint was the change from baseline to Week 4 in peak FEV1 (maximum value during $3 \mathrm{~h}$ postdose, $0-3 \mathrm{~h}$ ), placebo and tiotropium adjusted.

Secondary endpoints included the placebo and tiotropium adjusted change from baseline in: average area under the curve (AUC) 0-3h FEV1, average AUC0-12h FEV1 at Day 1 and Week 4, peak FEV1 at Day 1 and Weeks 1-3; morning trough FEV1 at Weeks 1-4. QoL and symptom improvement was assessed with the placebo and tiotropium adjusted change from baseline in: the SGRQ-C at Weeks 2 and 4; mean weekly values over Weeks 1 to 4 in COPD symptoms, as measured by E-RS ${ }^{\mathrm{TM}}$ : COPD; TDI at Weeks 2 and 4; and mean weekly values over Weeks 1 to 4 in rescue medication use. Compliance with blinded study medication was assessed via returned vials and captured in the eDiary. Compliance with tiotropium dosing was captured in the eDiary. The time of dosing was not collected.

\section{Safety}

Ensifentrine safety was assessed by evaluation of incidence of treatment-emergent adverse events (TEAEs), laboratory safety tests, pre- and post-dose 12-lead ECG data (including mean heart rate and QTcF interval), and vital signs.

\section{Statistical Analysis}

The standard deviation for the change in peak FEV1 was estimated to be $200 \mathrm{~mL}$. With a 2 -sided test at a $5 \%$ significance level and 73 evaluable patients per group, there was $80 \%$ power to detect a true difference of $93 \mathrm{~mL}$ between any two treatments. This detectable limit was considered sufficient to identify an effective dose of ensifentrine added on to tiotropium. Assuming a $10 \%$ early withdrawal rate, 80 patients per group were randomized.

Efficacy data analysis was performed on the full analysis set, which comprised all randomized and treated patients with sufficient data collected after intake of study medication to compute the pharmacodynamic parameters based on FEV1 on at least one occasion. The primary endpoint (Week 4 peak FEV1) was analyzed using a restricted maximum likelihood-based mixed 
model for repeated measured (MMRM), including fixed effects for treatment, visit and treatment by visit interaction, patient as random effect, baseline value as covariate and covariance structure by visit. Ensifentrine-placebo differences with $95 \%$ confidence intervals and corresponding two-sided p-values were calculated. To control for the familywise error rate, a fixed-sequence testing strategy was employed, with the highest ensifentrine dose (3 mg) tested vs placebo. If a statistically significant difference was found at the two-sided $\alpha$ level of $5 \%$, the testing proceeded with the next lower dose. If a test was nonsignificant, testing stopped and the remaining null hypotheses accepted. The average FEV1 endpoints were calculated using the linear trapezoidal method as the area under the curve divided by the length of the time interval of interest.

A similar MMRM method was used to analyze most of the secondary efficacy endpoints, with the same hierarchical testing within endpoint, although endpoints were tested independently. In the analysis of TDI, BDI was used as baseline in the model and the dependent variable was the TDI total score. Weekly mean values were used for the MMRM analysis of E-RSTM: COPD and the use of rescue medication and baseline for both measures was computed over the last 7 days of the run-in period. Values at Weeks 2 and 4 were used for the MMRM analysis of TDI, as well as the change from baseline in SGRQ-C.

\section{Results}

The study was conducted between May and November 2019 at 46 study centers across the United States (USA), although 49 centers consented at least one patient.

\section{Disposition}

Overall, 416 patients were randomized. Of those, 413 $(99.3 \%)$ received at least one dose of blinded study medication and were included in the full analysis set as well as the safety analysis set. A total of 373 (89.7\%) patients completed the 4-week study. Figure 1 illustrates patient disposition for the study.

The most common reasons for early study discontinuation were protocol deviations $(\mathrm{n}=20,46.5 \%)$, largely driven by patients not meeting randomization criteria (eg, recent COPD exacerbation, asthma or other respiratory disorder, or intolerance to tiotropium), and withdrawal by patient ( $\mathrm{n}=13,30.2 \%)$. A higher proportion of patients in the $0.75 \mathrm{mg}$ arm discontinued the study early compared to other treatments arms $(\mathrm{n}=15,17.6 \%$ vs $6.0-12.0 \%)$. There were no deaths during the study.

\section{Compliance}

Based on the number of vials dispensed and returned, mean treatment compliance was high ( $\geq 97.7 \%)$ and similar across arms. Median duration of exposure was 29.0 days across all groups.

\section{Characteristics}

Baseline population characteristics for the full analysis set $(n=413)$ are listed in Table 1 . The majority of patients were White $(90.1 \%)$, with a mean age of 64.3 years (range: 45 to 80 years). Over half $(57.5 \%)$ were female and $52.2 \%$ were less than 65 years of age. There were 214 non-reversible (33.2\% male) and 199 reversible (52.8\% male) patients.

Baseline disease and clinical characteristics are also displayed in Table 1. Mean pre-bronchodilator FEV1 of 1.20 L, mean post-bronchodilator FEV1 of $1.40 \mathrm{~L}(50.2 \%$ of predicted normal FEV1) and an FEV1/FVC ratio of 0.52 . Mean baseline reversibility was 87.0 and $321.4 \mathrm{~mL}$ for non-reversible and reversible strata, respectively. The $0.375 \mathrm{mg}$ arm had the highest percentage of patients that self-reported a diagnosis of chronic bronchitis $(67.5 \%$ vs $51.2-62.7 \%)$ as well as previous LAMA users (56.6\% vs 34.6-51.2\%). The placebo arm had the highest percentages of males (47.6\% vs $37.0-45.1 \%)$ and current smokers (63.1\% vs $49.4-59.0 \%)$, in addition to highest baseline mean PRO scores (SGRQ-C and E-RSTM: COPD total scores) and rescue medication use (Table 2).

\section{Primary Endpoint}

Ensifentrine resulted in a dose-dependent, statistically significant improvement in peak FEV1, compared to the placebo arm when added to tiotropium. Least-squares mean (LSM) placebo-corrected differences for the $0.375,0.75$, 1.5 and $3 \mathrm{mg}$ arms were as follows: 77.5 ( $\mathrm{p}=0.037 ; 95 \%$ CI: 4.8, 150.1); 91.2 ( $\mathrm{p}=0.015 ; 95 \%$ CI: 18.0, 164.3); 107.2 $(\mathrm{p}=0.004$; 95\% CI: 34.4, 180.0); and $124.2 \mathrm{~mL}(\mathrm{p}<0.001$; 95\% CI: 51.7, 196.8) respectively (Table 3, Figure 2).

\section{Other Endpoints}

A statistically significant improvement was observed in peak FEV1 at Day 1 and Weeks $1-3$ in all ensifentrine arms compared to the placebo arm (LSM placebo-corrected difference, all $\mathrm{p}<0.02$, Figure 2, Supplement Table 5). 


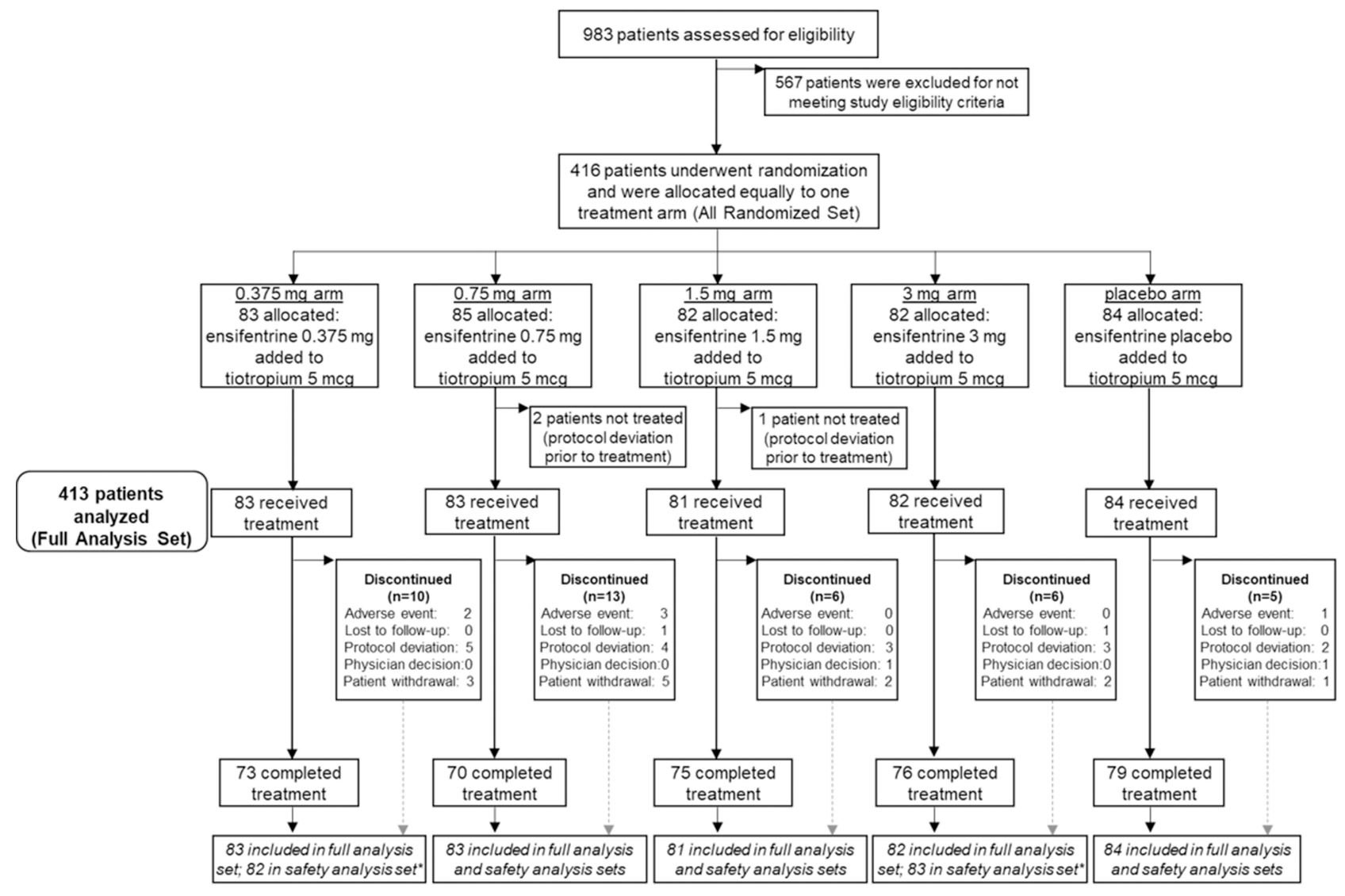

Figure I Patient flow through the study.

Notes: Tiotropium: open-label tiotropium (two puffs $2.5 \mu \mathrm{g}$; once daily). Ensifentrine: double-blind study medication (via jet nebulizer with compressor; $0.375 \mathrm{mg}, 0.75 \mathrm{mg}$, $1.5 \mathrm{mg}, 3 \mathrm{mg}$, or placebo; twice daily). Full analysis set: all randomized patients with sufficient data collected after intake of blinded study medication to compute the pharmacodynamic parameters based on FEVI on at least one occasion $(n=4 \mid 3)$. Safety analysis set: all patients that received at least one dose of study medication ( $n=4 \mid 3)$. *One patient was dispensed $3 \mathrm{mg}$ drug dosing rather than $0.375 \mathrm{mg}$.

Abbreviations: FEVI, forced expiratory volume in Isecond; $n$, number of patients.

A dose-ordered response in the change from baseline in average FEV1 over $12 \mathrm{~h}$ at Week 4 was also observed with a statistically significant improvement for the $3 \mathrm{mg}$ arm (LSM placebo-corrected difference; $87.3 \mathrm{~mL} ; 95 \% \mathrm{CI}$ : 20.0, 154.5; $\mathrm{p}=0.011$; Table 2). Separation from placebo was maintained over $12 \mathrm{~h}$ with the $3 \mathrm{mg}$ arm as well, as demonstrated in the $12 \mathrm{~h}$ spirometry profile at Week 4 (Supplement Figure 2).

A nominal improvement from baseline in morning trough FEV1 at Week 4 was observed with the $3 \mathrm{mg}$ arm compared to the placebo arm $(27.2 \mathrm{~mL}$; Table 3$)$. However, there were no statistically significant improvements from baseline in trough FEV1 for any of the treatment arms (Table 3).

Post-hoc analysis of average FEV1 6-12h from baseline to Week 4 with blinded study drug added to tiotropium revealed nominal improvements. LSM placebocorrected differences were $5(0.375 \mathrm{mg}$ arm; $\mathrm{p}=0.884$, 95\% CI: $-59,69) ; 33$ (0.75 mg arm; $p=0.314,95 \%$ CI:
$-31,97) ; 27$ (1.5 mg arm; $\mathrm{p}=0.407,95 \% \mathrm{CI}:-37,92)$; and $58 \mathrm{~mL}$ (3 mg arm; $\mathrm{p}=0.078,95 \%$ CI: $-6,122)$.

In COPD health-related QoL and symptoms, ensifentrine showed statistically significant improvements in SGRQ-C (LSM change from baseline) compared to placebo, exceeding the minimal clinically important difference (MCID) of 4 units at Week 4 with the 1.5 and $3 \mathrm{mg}$ arms (LSM placebo-corrected differences; both $\mathrm{p}<0.05$, Table 4). Compared to the placebo arm, ensifentrine generally provided numerically greater improvements at Week 4 in the E-RS TM: COPD total score and TDI score, but did not reach statistical significance (Table 4). There were minimal changes from baseline in rescue medication use compared to the placebo arm (Supplement Table 6).

\section{Safety}

Overall, the AE profile of all ensifentrine treatment arms were similar to the placebo arm. Ensifentrine was well 
Table I Baseline Demographics and Disease Characteristics in the Full Analysis Set

\begin{tabular}{|c|c|c|c|c|c|c|}
\hline & \multicolumn{5}{|c|}{ Ensifentrine Treatment $\mathrm{Arm}^{\dagger}(\mathrm{n})$} & \multirow{2}{*}{$\begin{array}{c}\text { Total } \\
(n=4 \mid 3)\end{array}$} \\
\hline & $\begin{array}{c}0.375 \mathrm{mg} \text { Arm } \\
(\mathrm{n}=83)\end{array}$ & $\begin{array}{c}0.75 \mathrm{mg} \text { Arm } \\
(\mathrm{n}=83)\end{array}$ & $\begin{array}{c}1.5 \mathrm{mg} \text { Arm } \\
(\mathrm{n}=8 \mathrm{I})\end{array}$ & $\begin{array}{c}3 \mathrm{mg} \text { Arm } \\
(\mathrm{n}=82)\end{array}$ & $\begin{array}{l}\text { Placebo Arm } \\
\quad(n=84)\end{array}$ & \\
\hline \multicolumn{7}{|l|}{ Age } \\
\hline Mean, years (SD) & $64.2(7.86)$ & $65.5(8.43)$ & $63.8(7.7 I)$ & $64.5(7.92)$ & $63.6(8.4 I)$ & $64.3(8.06)$ \\
\hline$<65$ years, \% & 53.0 & 45.8 & 54.3 & 50.0 & 56.0 & 51.8 \\
\hline \multicolumn{7}{|l|}{ Gender, \% } \\
\hline Male & 38.6 & 44.6 & 37.0 & 45.1 & 47.6 & 42.6 \\
\hline Female & 61.4 & 55.4 & 63.0 & 54.9 & 52.4 & 57.4 \\
\hline \multicolumn{7}{|l|}{ Race, \% } \\
\hline White & 88.0 & 91.6 & 88.9 & 92.7 & 89.3 & 90.1 \\
\hline Black or African American & 12.0 & 8.4 & 11.1 & 7.3 & 10.7 & 9.9 \\
\hline \multicolumn{7}{|l|}{ Reversible, \% } \\
\hline Yes & 45.8 & 47.0 & 49.4 & 50.0 & 48.8 & 48.2 \\
\hline No & 54.2 & 53.0 & 50.6 & 50.0 & 51.2 & 51.8 \\
\hline \multicolumn{7}{|l|}{ Baseline FEVI } \\
\hline Mean post-bronchodilator $\mathrm{FEV}_{1}, \mathrm{~L}$ (SD) & $1.4(0.46)$ & $\mathrm{I} .4(0.44)$ & $1.4(0.38)$ & $1.4(0.45)$ & $1.4(0.46)$ & I.4 (0.44) \\
\hline $\begin{array}{l}\text { Post-bronchodilator } \mathrm{FEV}_{1}, \% \text { predicted } \\
\text { normal (SD) }\end{array}$ & $50.4(10.18)$ & $50.9(9.67)$ & $49.9(10.12)$ & $50.4(|0.6|)$ & $48.9(10.93)$ & $50.1(10.29)$ \\
\hline Mean FEV, reversibility, mL (SD) & I89.8 (140.94) & $209.3(147.47)$ & $203.9(\mid 77.91)$ & $214.2(|45.7|)$ & $185.5(143.69)$ & $200.5(151.28)$ \\
\hline \% reversibility $(\mathrm{SD})$ & $18.2(13.63)$ & I8.1 (13.34) & $21.0(19.69)$ & $20.2(14.74)$ & $17.6(14.19)$ & $19.0(15.25)$ \\
\hline Baseline mean mMRC (SD) & $2.7(0.63)$ & $2.7(0.59)$ & $2.6(0.57)$ & $2.6(0.59)$ & $2.7(0.62)$ & $2.7(0.60)$ \\
\hline \multicolumn{7}{|l|}{ Reported to have chronic bronchitis, \% ${ }^{\mathrm{C}}$} \\
\hline Yes & 67.5 & 62.7 & 56.8 & 51.2 & 56.0 & 58.8 \\
\hline No & 32.5 & 37.3 & 43.2 & 48.8 & 44.0 & 41.2 \\
\hline \multicolumn{7}{|l|}{ Smoking history ${ }^{X}$} \\
\hline Current smoker, \% & 49.4 & 59.0 & 51.9 & 52.4 & 63.1 & 55.2 \\
\hline Ex-smoker, \% & 50.6 & 41.0 & 48.1 & 47.6 & 36.9 & 44.8 \\
\hline Mean smoking exposure, pack years (SD) & $52.9(26.14)$ & $52.5(26.39)$ & $50.5(25.54)$ & $51.0(20.56)$ & $52.5(27.37)$ & $51.9(25.22)$ \\
\hline \multicolumn{7}{|l|}{ Prior COPD medication, \% } \\
\hline LAMA & 56.6 & 44.6 & 34.6 & 39.0 & 51.2 & 45.3 \\
\hline LABA/LAMA & 13.3 & 16.9 & 25.9 & 19.5 & 19.0 & 18.9 \\
\hline ICS/LABA & 10.8 & 12.0 & 16.0 & 6.1 & 15.5 & 12.1 \\
\hline ICS & 4.8 & 3.6 & 2.5 & 0 & 2.4 & 2.7 \\
\hline LABA & 1.2 & 4.8 & 2.5 & 0 & 2.4 & 2.2 \\
\hline ICS/LABA/LAMA & 1.2 & 0 & 1.2 & 3.7 & 2.4 & 1.7 \\
\hline
\end{tabular}

Notes: ${ }^{C}$ Reported chronic bronchitis: patients were asked if they had been diagnosed with chronic bronchitis (yes or no; defined as productive cough and sputum production on most days for 3 months in each of 2 consecutive years; Pauwels et al 200I). ${ }^{15}$ tDouble-blind study medication (ensifentrine 0.375 , 0.75 , I.5 or 3 mg or placebo BID) added to once-daily tiotropium QD. ${ }^{\times}$Current and former smokers with smoking history of $\geq 10$ pack years. Baseline, post 2 weeks receiving tiotropium.

Abbreviations: BID, twice daily; COPD, chronic obstructive pulmonary disease; FEVI, forced expiratory volume in I second; ICS, inhaled corticosteroid; LAMA, longacting muscarinic antagonist; LABA, long-acting beta agonist; mMRC, modified medical research council dyspnea scale; $n$, number of patients; Pack-years, the number of packs per day multiplied by the number of years smoking; QD, once daily; SD, standard deviation; reversible, $\geq 12 \%$ and $\geq 200 \mathrm{~mL}$ increase in FEVI post 4 puffs albuterol; nonreversible, $<12 \%$ or $<200 \mathrm{~mL}$ increase in FEVI post 4 puffs albuterol.

tolerated at all dose levels and there were no patterns or relationship to ensifentrine dose observed. Gastrointestinal and cardiac disorders were rare overall.

Table 5 provides the overall summary of TEAEs as well as those most commonly reported in more than one patient overall by preferred term. The most commonly reported TEAE in patients that received ensifentrine was headache $(1.8 \%$ [6/329] vs $1.2 \%$ [1/84] that received placebo). In patients that received ensifentrine, $0.91 \%(3 / 329)$ reported serious TEAE; however, there were no reports of serious drug-related TEAE. There were no meaningful changes in vital signs, blood pressure or pulse-rate and 
Table 2 Baseline Patient-Reported Outcome (PRO) Scores and Rescue Medication Use for Patients with Baseline and Week 4 Values Reported in the Full Analysis Set

\begin{tabular}{|c|c|c|c|c|c|}
\hline & \multicolumn{5}{|c|}{ Ensifentrine Treatment $\mathrm{Arm}^{\dagger}$ (n) } \\
\hline & $\begin{array}{c}0.375 \mathrm{mg} \text { Arm } \\
(\mathrm{n}=83)\end{array}$ & $\begin{array}{c}0.75 \mathrm{mg} \text { Arm } \\
\quad(n=83)\end{array}$ & $\begin{array}{c}1.5 \mathrm{mg} \text { Arm } \\
(n=8 I)\end{array}$ & $\begin{array}{c}3 \text { mg Arm } \\
(n=82)\end{array}$ & $\begin{array}{l}\text { Placebo Arm } \\
\quad(n=84)\end{array}$ \\
\hline \multicolumn{6}{|l|}{ SGRQ-C Total Score } \\
\hline$n^{\wedge}$ & 75 & 69 & 71 & 73 & 76 \\
\hline Baseline mean (range) & $55.9(20.6,96.6)$ & $51.9(14.4,85.4)$ & $54.7(16.0,96.5)$ & $52.9(8.1,91.4)$ & $58.3(21.2,99.5)$ \\
\hline \multicolumn{6}{|l|}{ E-RS TM: COPD Total Score } \\
\hline $\mathrm{n}^{\wedge}$ & 75 & 69 & 75 & 74 & 77 \\
\hline Baseline mean (range) & I2.4 (0.0, 29.8) & $12.4(0.0,26.3)$ & $12.7(0.0,27.6)$ & $12.2(0.0,24.2)$ & $14.2(1.2,30.3)$ \\
\hline \multicolumn{6}{|l|}{ Baseline Dyspnea Index } \\
\hline $\mathrm{n}^{\wedge}$ & 77 & 74 & 75 & 78 & 80 \\
\hline Baseline mean (range) & $5.9(4.0,8.0)$ & $5.9(1.0,8.0)$ & $5.7(0.0,9.0)$ & $6.0(1.0,12.0)$ & $5.6(0.0,9.0)$ \\
\hline \multicolumn{6}{|l|}{$\begin{array}{l}\text { Rescue Medication Use, } \\
\text { puffs/day }\end{array}$} \\
\hline $\mathrm{n}^{\wedge}$ & 74 & 68 & 72 & 71 & 76 \\
\hline Baseline mean (range) & $2.1(0.0,8.0)$ & $2.4(0.0,9.7)$ & $2.1(0.0,10.6)$ & $2.1(0.0,10.6)$ & $2.7(0.0,13.6)$ \\
\hline
\end{tabular}

Notes: ${ }^{\dagger}$ Double-blind study medication (ensifentrine $0.375,0.75$, 1.5 or $3 \mathrm{mg}$ or placebo BID) added to once-daily tiotropium QD. ${ }^{\wedge}$ Number of patients with valid values at baseline and at Week 4 visits. Baseline, post 2 weeks receiving tiotropium.

Abbreviations: E-RSTM: COPD, Evaluating Respiratory Symptoms in COPD; SGRQ-C, St. George's Respiratory Questionnaire for COPD patients.

Table 3 Change from Baseline to Week 4 in Peak FEVI (Over 3 Hours), Average FEVI (0-I2 Hours) and Morning Trough FEVI in the Full Analysis Set

\begin{tabular}{|c|c|c|c|c|c|}
\hline & \multicolumn{5}{|c|}{ Ensifentrine Treatment $\mathrm{Arm}^{\dagger}(\mathrm{n})$} \\
\hline & $\begin{array}{c}0.375 \mathrm{mg} \text { Arm } \\
(\mathrm{n}=83)\end{array}$ & $\begin{array}{c}0.75 \mathrm{mg} \text { Arm } \\
(\mathrm{n}=83)\end{array}$ & $\begin{array}{l}1.5 \mathrm{mg} \text { Arm } \\
(\mathrm{n}=8 \mathrm{I})\end{array}$ & $\begin{array}{c}3 \mathrm{mg} \text { Arm } \\
(\mathrm{n}=82)\end{array}$ & $\begin{array}{l}\text { Placebo Arm } \\
\qquad(n=84)\end{array}$ \\
\hline \multicolumn{6}{|l|}{$\begin{array}{l}\text { Week } 4 \text { Peak FEVI ( } 0-3 h \text { ) (change from } \\
\text { baseline) }\end{array}$} \\
\hline LS mean, mL $(95 \% \mathrm{Cl})$ & $196(144,248)$ & $210(157,263)$ & $226(174,278)$ & $243(191,295)$ & $119(68,170)$ \\
\hline $\begin{array}{l}\text { Treatment - placebo difference, LS } \\
\text { mean, } \mathrm{mL}(95 \% \mathrm{Cl})\end{array}$ & $78(5,150)$ & $91(18,164)$ & $107(34,180)$ & $124(52,197)$ & \\
\hline $\mathrm{p}$-value & 0.037 & 0.015 & 0.004 & 0.001 & \\
\hline \multicolumn{6}{|c|}{$\begin{array}{l}\text { Week } 4 \text { Average FEVI (0-I2h) (change from } \\
\text { baseline) }\end{array}$} \\
\hline LS mean, mL $(95 \% \mathrm{Cl})$ & $36(-12,84)$ & $63(14,112)$ & $64(16,112)$ & $97(49,145)$ & $10(-38,57)$ \\
\hline $\begin{array}{l}\text { Treatment - placebo difference, LS } \\
\text { mean, } \mathrm{mL}(95 \% \mathrm{Cl})\end{array}$ & $26(-4 I, 94)$ & $53(-15,121)$ & $54(-13,122)$ & $87(20,155)$ & \\
\hline $\mathrm{p}$-value & 0.446 & 0.124 & 0.115 & 0.011 & \\
\hline \multicolumn{6}{|c|}{$\begin{array}{l}\text { Week } 4 \text { Morning trough FEVI (change from } \\
\text { baseline) }\end{array}$} \\
\hline LS mean, mL $(95 \% \mathrm{Cl})$ & $-20(-65,25)$ & $-35(-8 I, 12)$ & $-14(-60,31)$ & $5(-40,5 I)$ & $-22(-66,23)$ \\
\hline $\begin{array}{l}\text { Treatment - placebo difference, LS } \\
\text { mean, } \mathrm{mL}(95 \% \mathrm{Cl})\end{array}$ & $2(-62,65)$ & $-13(-77,51)$ & $8(-56,7 I)$ & $27(-36,91)$ & \\
\hline $\mathrm{P}$-value & 0.959 & 0.691 & 0.812 & 0.400 & \\
\hline
\end{tabular}

Notes: Data are least squares mean treatment - placebo differences, both added on to tiotropium ( $95 \% \mathrm{Cl})$; $\mathrm{p}$-value ( $\mathrm{p}<0.05$ is significant). ${ }^{\dagger}$ Double-blind study medication (ensifentrine $0.375,0.75,1.5$ or $3 \mathrm{mg}$ or placebo BID) added to once-daily tiotropium QD. Baseline, post 2 weeks receiving tiotropium.

Abbreviations: BID, twice daily; $\mathrm{Cl}$, confidence interval; COPD, chronic obstructive pulmonary disease; FEVI, forced expiratory volume in I second; LS, least squares; $\mathrm{n}$, number of patients in full analysis set; placebo, ensifentrine placebo added to tiotropium; QD, once daily. 


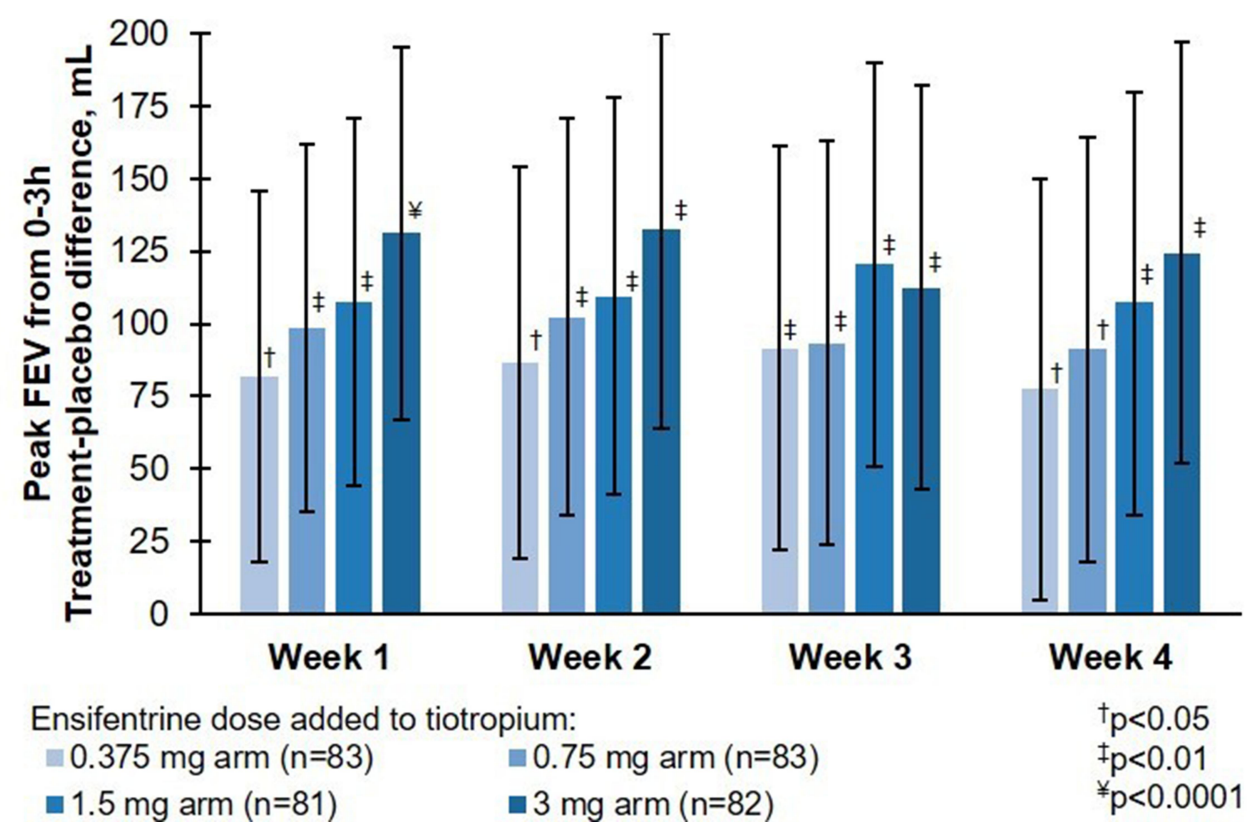

Figure 2 Peak FEVI between 0 and $3 \mathrm{~h}$ post-dose in the full analysis set.

Notes: Mean change from baseline $\mathrm{FEV}_{\mathrm{I}}$ and standard error of mean are shown. Data are least squares means treatment - placebo differences and $95 \% \mathrm{Cl}$ of the least squares mean difference. ${ }^{\dagger} \mathrm{P}<0.05$ vs placebo; ${ }^{\ddagger} \mathrm{P}<0.01$ vs placebo; ${ }^{\ddagger} \mathrm{P}<0.000 \mathrm{I}$ vs placebo. Least squares mean changes from baseline in the placebo ensifentrine added to tiotropium arm in the full analysis set (placebo, $\mathrm{n}=84$ ) were 104, 110,107 , and $119 \mathrm{~mL}$ at Weeks I, 2, 3 and 4, respectively. Baseline, post 2 weeks receiving tiotropium. Abbreviations: $\mathrm{Cl}$, confidence interval; $\mathrm{FEVI}$, forced expiratory volume in Isecond; p, p-value vs placebo; placebo, placebo ensifentrine added to tiotropium.

no dose-related or meaningful changes in heart rate nor to QTcF interval, pre-dose or $2 \mathrm{~h}$ post-dose. Baseline, Week 4 and change from baseline to Week 4 values of ECG mean heart rate and ECG QTcF interval are shown in $\underline{\text { Supplement Tables } 7}$ and $\underline{8}$.

\section{Discussion}

In this double-blind, placebo-controlled, randomized, dose-ranging study, twice-daily, nebulized ensifentrine (0.375-3 mg) improved peak FEV1 (0-3h) in a doseordered, statistically significant manner with all ensifentrine doses added to tiotropium QD compared to placebo added to tiotropium QD after 4 weeks $(0.375 \mathrm{mg}: 78 \mathrm{~mL}$, $\mathrm{p}=0.037 ; 0.75 \mathrm{mg}: 91 \mathrm{~mL}, \mathrm{p}=0.015 ; 1.5 \mathrm{mg}$ : $107 \mathrm{~mL}$, $\mathrm{p}=0.004 ; 3 \mathrm{mg}: 124 \mathrm{~mL}, \mathrm{p}<0.001)$. This outcome is similar to the previously reported dose-ranging study of ensifentrine monotherapy ( 0.75 to $6 \mathrm{mg}$ or placebo) in COPD patients, where ensifentrine significantly improved peak FEV1 (0-3h) compared to placebo for all doses after 4 weeks of treatment and showed a similar dose response up to the $3 \mathrm{mg}$ arm. ${ }^{12}$

There were dose-dependent improvements in lung function observed for average AUC0-12h FEV1, including a statistically significant improvement of $87 \mathrm{~mL}$ with the $3 \mathrm{mg}$ arm, which appeared to be the most efficacious dose for airflow improvements over the $12 \mathrm{~h}$ serial spirometry. Nominal, but consistent improvements in trough FEV1 with the $3 \mathrm{mg}$ arm were also observed, which were smaller in magnitude in this study compared to prior Phase $2 b$ study CO-203 due to the background tiotropium use in the current study. These results are also consistent with those observed in the earlier ensifentrine monotherapy study, where statistically significant improvements of $119 \mathrm{~mL}$ versus placebo (average FEV1 AUC 0-12h) and $68 \mathrm{~mL}$ (morning trough FEV1) were shown with the $3 \mathrm{mg} \mathrm{arm} .^{12}$

Ensifentrine added on to tiotropium produced a robust, clinically meaningful and statistically significant improvement in QoL (measured with SGRQ-C) after 4 weeks that were supported by numerical improvements in COPD symptoms (measured by E-RS ${ }^{\mathrm{TM}}$ : COPD and TDI) compared to placebo added on to tiotropium. This represents an unprecedented improvement in quality of life over only 4 weeks of treatment in patients with COPD who continued to have impaired lung function and remain highly symptomatic despite maintenance use of tiotropium. The magnitude of improvement observed in quality of life added on to tiotropium, compared to placebo added on to tiotropium appears to be greater than the incremental improvements in lung function would predict and included improvements in all SGRQ-C sub-scales, with the largest 
Table 4 Change from Baseline to Week 4 in SGRQ-C Total Score, E-RSTM: COPD Total Score and TDI Score in the Full Analysis Set

\begin{tabular}{|c|c|c|c|c|c|}
\hline & \multicolumn{5}{|c|}{ Ensifentrine Treatment $\mathrm{Arm}^{\dagger}(\mathrm{n})$} \\
\hline & $\begin{array}{c}0.375 \mathrm{mg} \text { Arm } \\
(\mathrm{n}=83)\end{array}$ & $\begin{array}{c}0.75 \mathrm{mg} \text { Arm } \\
(\mathrm{n}=83)\end{array}$ & $\begin{array}{c}1.5 \mathrm{mg} \text { Arm } \\
(\mathrm{n}=8 \mathrm{I})\end{array}$ & $\begin{array}{c}3 \mathrm{mg} \text { Arm } \\
(\mathrm{n}=82)\end{array}$ & $\begin{array}{l}\text { Placebo Arm } \\
\quad(n=84)\end{array}$ \\
\hline \multicolumn{6}{|l|}{$\begin{array}{l}\text { Week } 4 \text { SGRQ-C Total Score (change from } \\
\text { baseline) }\end{array}$} \\
\hline LS mean $(95 \% \mathrm{Cl})$ & $-4.4(-6.96,-1.83)$ & $-2.4(-5.10,0.30)$ & $-4.9(-7.52,-2.22)$ & $-4.2(-6.8|,-| .5 \mid)$ & $-0.1(-2.71,2.48)$ \\
\hline $\begin{array}{l}\text { Treatment - placebo difference, LS mean } \\
(95 \% \mathrm{Cl})\end{array}$ & $-4.3(-7.92,-0.62)$ & $-2.3(-6.04,1.47)$ & $-4.8(-8.46,-1.05)$ & $-4.1(-7.76,-0.33)$ & \\
\hline $\mathrm{P}$-value & 0.022 & 0.232 & 0.012 & 0.033 & \\
\hline \multicolumn{6}{|l|}{$\begin{array}{l}\text { Week } 4 \text { E-RS TM: COPD Total Score (change } \\
\text { from baseline) }\end{array}$} \\
\hline LS mean $(95 \% \mathrm{Cl})$ & $-1.7(-2.54,-0.84)$ & $-0.6(-1.46,0.27)$ & $-1.2(-2.08,-0.37)$ & $-1.1(-1.93,-0.21)$ & $-0.2(-1.08,0.62)$ \\
\hline $\begin{array}{l}\text { Treatment - placebo difference, LS mean } \\
(95 \% \mathrm{Cl})\end{array}$ & $-1.5(-2.67,-0.26)$ & $-0.4(-1.58,0.85)$ & $-1.0(-2.20,0.21)$ & $-0.8(-2.05,0.37)$ & \\
\hline $\mathrm{p}$-value & 0.018 & 0.555 & 0.105 & 0.171 & \\
\hline \multicolumn{6}{|l|}{ Week 4 Transition Dyspnea Index (TDI) } \\
\hline \multicolumn{6}{|l|}{ Score (change from baseline) } \\
\hline LS mean $(95 \% \mathrm{Cl})$ & $2.1(1.42,2.76)$ & $1.5(0.80,2.17)$ & $2.1(1.37,2.74)$ & $2.1(1.39,2.74)$ & $1.8(1.10,2.43)$ \\
\hline $\begin{array}{l}\text { Treatment - placebo difference, LS mean } \\
(95 \% \mathrm{Cl})\end{array}$ & $0.3(-0.62,1.27)$ & $-0.3(-1.24,0.68)$ & $0.3(-0.66,1.24)$ & $0.3(-0.65,1.25)$ & \\
\hline $\mathrm{p}$-value & 0.503 & 0.563 & 0.551 & 0.538 & \\
\hline
\end{tabular}

Notes: Data are least squares mean treatment - placebo differences, both added on to tiotropium ( $95 \% \mathrm{Cl}$ ); $\mathrm{p}$-value ( $\mathrm{p}<0.05$ is significant for the treatment-placebo difference in the Week 4 SGRQ-C total score with the 1.5 and $3 \mathrm{mg}$ arms). ${ }^{\dagger}$ Double-blind study medication (ensifentrine $0.375,0.75,1.5$ or 3 mg or placebo BID) added to once-daily tiotropium QD. Baseline, post 2 weeks receiving tiotropium.

Abbreviations: $\mathrm{BID}$, twice daily; $\mathrm{Cl}$, confidence interval; COPD, chronic obstructive pulmonary disease; E-RS ${ }^{\mathrm{TM}}$ : COPD, Evaluating Respiratory Symptoms in COPD; FEVI, forced expiratory volume in I second; LS, least squares; MCID, minimally important clinical difference (4 units for SGRQ-C, 2 units for E-RSTM: COPD, and I unit for TDI); $\mathrm{n}$, number of patients in full analysis set; placebo, ensifentrine placebo added to tiotropium; QD, once daily; SGRQ-C, St. George's Respiratory Questionnaire for COPD Patients.

improvements demonstrated in the Activity and Impacts domains. This suggests that the dual PDE3/4 mechanism by which ensifentrine acts is providing benefits beyond bronchodilation, and possibly related to anti-inflammatory effects. The data on lung function, symptoms and quality of life improvement described herein, support the twicedaily dosing of ensifentrine in patients with moderate-tosevere COPD as a potential add-on to maintenance bronchodilators for symptomatic COPD patients who may benefit from escalation of therapy.

As observed with the earlier ensifentrine monotherapy study, delivery of ensifentrine directly to the airways through nebulization in addition to tiotropium was well tolerated at all doses in this study with an adverse event profile similar to the placebo arm, including the cardiovascular and gastrointestinal effects.

This study was not enriched with exacerbation-prone patients, and the 4-week treatment duration was too brief to assess ensifentrine doses for potential prevention of COPD exacerbations. However, another approved oral PDE4 antagonist, roflumilast 500mg daily, has reported decreases in COPD exacerbation rates in at least some subgroups of COPD patients, ${ }^{16}$ suggesting ensifentrine might also favorably modify COPD exacerbations in a long-term COPD-exacerbation prone population. In delivering ensifentrine directly to the airways through nebulization, the medication appeared well tolerated. There were very few reports of treatment-related nausea and headache or other adverse events often reported for roflumilast or other systemically delivered phosphodiesterase therapies.

\section{Limitations}

The run-in period with tiotropium prior to randomization was 2 weeks in order to achieve steady state on bronchodilation, and it is possible that this was not long enough to establish a robust baseline for patient-reported outcome measures and rescue medication use. Furthermore, this study enrolled $50 \%$ of patients who showed evidence of reversibility to albuterol at screening in order to better characterize responsiveness to ensifentrine in patients with COPD. The impact of this design feature combined with the relatively short run-in on tiotropium on study 
Table 5 Proportion of Treatment Emergent Adverse Events Summary Listed by Prevalence in the Safety Analysis Set

\begin{tabular}{|c|c|c|c|c|c|}
\hline & \multicolumn{5}{|c|}{ Ensifentrine Treatment $\mathrm{Arm}^{\dagger}$ (n) } \\
\hline & $\begin{array}{c}0.375 \mathrm{mg} \\
\text { Arm }(n=82)\end{array}$ & $\begin{array}{c}0.75 \mathrm{mg} \\
\text { Arm (n=83) }\end{array}$ & $\begin{array}{c}1.5 \mathrm{mg} \text { Arm } \\
(\mathrm{n}=8 \mathrm{I})\end{array}$ & $\begin{array}{c}3 \text { mg Arm } \\
(n=83)\end{array}$ & $\begin{array}{c}\text { Placebo } \\
\text { Arm }(n=84)\end{array}$ \\
\hline Any TEAE, \% & 14.6 & I8. I & 17.3 & 21.7 & 20.2 \\
\hline Any TEAE leading to drug discontinuation, $\%$ & 2.4 & 3.6 & 0 & 0 & 1.2 \\
\hline Any drug-related TEAE, \% & 1.2 & 3.6 & 2.5 & 2.4 & 4.8 \\
\hline Any serious TEAE, \% & 0 & 1.2 & 0 & 2.4 & 0 \\
\hline Any serious drug related TEAE, \% & 0 & 0 & 0 & 0 & 0 \\
\hline Any serious TEAE leading to drug discontinuation, \% & 0 & 1.2 & 0 & 0 & 0 \\
\hline Any TEAE leading to death, $\%$ & 0 & 0 & 0 & 0 & 0 \\
\hline \multicolumn{6}{|l|}{$\begin{array}{l}\text { Most commonly reported TEAEs by preferred term (>I } \\
\text { patient overall), \% }\end{array}$} \\
\hline $\mathrm{COPD}^{\mathrm{a}}$ & $3.6^{\mathrm{b}}$ & $2.4^{b}$ & 0 & $3.6^{\mathrm{c}}$ & 0 \\
\hline Headache & 2.4 & 1.2 & 1.2 & 2.4 & 1.2 \\
\hline Blood creatinine increased & 1.2 & 2.4 & 1.2 & 0 & 0 \\
\hline Oral candidiasis & 0 & 1.2 & 0 & 1.2 & 2.4 \\
\hline Blood pressure increased & 1.2 & 1.2 & 1.2 & 0 & 0 \\
\hline Dyspnea & 0 & 1.2 & 0 & 2.4 & 0 \\
\hline Nasopharyngitis & 0 & 0 & 0 & 1.2 & 2.4 \\
\hline Osteoarthritis & 1.2 & 0 & 1.2 & 1.2 & 0 \\
\hline Bronchitis & 0 & 1.2 & 0 & 0 & 1.2 \\
\hline Chest discomfort & 0 & 0 & 0 & 1.2 & 1.2 \\
\hline Contusion & 1.2 & 0 & 1.2 & 0 & 0 \\
\hline Cough & 0 & 0 & 0 & 1.2 & 1.2 \\
\hline Diarrhea & 0 & 1.2 & 0 & 1.2 & 0 \\
\hline Edema peripheral & 0 & 0 & 1.2 & 0 & 1.2 \\
\hline Fall & 0 & 1.2 & 1.2 & 0 & 0 \\
\hline Gastroenteritis & 0 & 0 & 2.5 & 0 & 0 \\
\hline Heart rate increased & 1.2 & 0 & 0 & 1.2 & 0 \\
\hline Muscle spasms & 0 & 2.4 & 0 & 0 & 0 \\
\hline
\end{tabular}

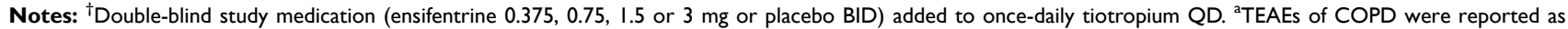
either worsening of COPD symptoms or COPD exacerbations. COPD exacerbations were reported as moderate TEAEs with PT of COPD that required treatment with systemic steroids for at least 3 days from or after the date of TEAE onset. 'Five (I.2\%) patients had COPD exacerbations (as defined above) reported: 3 (3.6\%) in the $0.375 \mathrm{mg}$ and $2(2.4 \%)$ in the $0.75 \mathrm{mg}$ arms. "Three (3.6\%) patients in the $3 \mathrm{mg}$ arm had events of "worsening of COPD symptoms" ( $\mathrm{n}=2$ ) and "mild COPD exacerbation" $(n=I)$ that were reported as mild TEAEs with PT of COPD.

Abbreviations: BID, twice daily; $\mathrm{Cl}$, confidence interval; COPD, chronic obstructive pulmonary disease; $\mathrm{n}$, number of patients in safety analysis set; placebo, ensifentrine placebo added to tiotropium; QD, once daily; TEAE, treatment emergent adverse event.

outcomes will be described in a subsequent publication. Trough FEV1 was assessed on a background of tiotropium, thus does not represent a true trough effect of ensifentrine. Additionally, as assessed in this study, the pre-dose morning trough assessment cannot be confirmed as 12-hours post evening dose as the timing of the evening dose prior to spirometry was not collected.

This dose-ranging study was powered for improvements in lung function, not symptom or QoL improvement. With approximately 80 patients randomized per arm, differences in baseline values for E-RS ${ }^{\mathrm{TM}}$ : COPD and SGRQ-C across treatment arms were observed, which may limit the interpretation of doseresponsiveness in these scales known to be impacted by baseline severity. Additionally, this was a shortterm study over a 4-week treatment period; thus, longerterm efficacy and safety needs to be established. In addition, potential benefits for nebulized PDE3/4 inhibitors such as ensifentrine for prevention of COPD exacerbations could not be evaluated in this short trial, 
and would require longer trials in COPD patients at risk for COPD exacerbations.

Strengths included the measurement of multiple endpoints to monitor airflow, health status and symptoms as well as safety, and the normalization of background maintenance therapy with sponsor provided tiotropium across the run-in and treatment periods.

\section{Conclusion}

Ensifentrine provided a dose-dependent, statistically significant and clinically meaningful bronchodilation (peak FEV1) of $78 \mathrm{~mL}(0.375 \mathrm{mg}), 91 \mathrm{~mL}(0.75 \mathrm{mg}), 107 \mathrm{~mL}(1.5 \mathrm{mg})$ and $124 \mathrm{~mL}(3 \mathrm{mg})$ when administered BID in addition to tiotropium (all $\mathrm{p}<0.05$ compared to placebo+tiotropium), in COPD patients who remained symptomatic while taking tiotropium. Additionally, this novel, inhaled inhibitor of PDE3 and PDE4, provided significant improvement in QoL and has a safety profile similar to placebo.

\section{Data Sharing Statement}

Individual participant data will not be shared. The study protocol and statistical analysis plan are shared at ClinicalTrials.gov (NCT03937479).

\section{Ethics Approval}

This study was approved by an institutional review board (Copernicus Group IRB of Cary, NC, USA).

\section{Acknowledgments}

This research was funded by Verona Pharma plc. The sponsor developed the study and funded the writing of the manuscript. Verona Pharma is the guarantor of the content of the manuscript, including the data and analysis.

\section{Author Contributions}

All authors made substantial contributions to conception and design, acquisition of data, or analysis and interpretation of data; took part in drafting the article or revising it critically for important intellectual content; agreed to submit to the current journal; gave final approval of the version to be published; and agree to be accountable for all aspects of the work.

\section{Disclosure}

Drs Ferguson and Kerwin served as an investigator for the study, received study grant from Verona Pharma, has received consulting fees from Verona Pharma. Dr Ferguson reports grants, personal fees, and/or non- financial support from Boehringer Ingelheim, GlaxoSmithKline, Novartis, Sunovion, Theravance/ Mylan, AstraZeneca, Innoviva, Circassia, Sanofi, Altvant, Knopp, Teva, Orpheris, DevPro, and Galderma, outside the submitted work. Dr Kerwin reports personal fees and non-financial support for consulting, advisory board membership, and travel reimbursement from Amphastar, AstraZeneca, Boehringer Ingelheim, Chiesi, Connect Biopharma, GlaxoSmithKline, Mylan, Novartis, Sunovion, and Theravance, outside the submitted work. Drs Rheault and Rickard are employees and shareholders for Verona Pharma. Mr Bengtsson serves as the biostatistical contractor for Verona Pharma. The authors report no other conflicts of interest in this work.

\section{References}

1. World Health Organization. Available from: https:/www.who.int/ news-room/fact-sheets/detail/the-top-10-causes-of-death. Accessed April 12, 2021.

2. Global Initiative for Chronic Obstructive Lung Disease. Global strategy for the diagnosis, management, and prevention of chronic obstructive pulmonary disease; 2020. Available from: https:/gold copd.org/gold-reports/. Accessed April 12, 2021.

3. Vestbo J, Papi A, Corradi M, et al. Single inhaler extrafine triple therapy versus long-acting muscarinic antagonist therapy for chronic obstructive pulmonary disease (TRINITY): a double-blind, parallel group, randomised controlled trial. Lancet. 2017;389 (10082):1919-1929. doi:10.1016/S0140-6736(17)30188-5

4. Mahler D, Decramer M, D’Urzo A, et al. Dual bronchodilation with QVA149 reduces patient-reported dyspnoea in COPD: the BLAZE study. Eur Respir J. 2014;43(6):1599-1609. doi:10.1183/ 09031936.00124013

5. Banner KH, Press NJ. Dual PDE3/4 inhibitors as therapeutic agents for chronic obstructive pulmonary disease. Br J Pharmacol. 2009;157 (6):892-906. doi:10.1111/j.1476-5381.2009.00170.x

6. De Boer J, Philpott AJ, Van Amsterdam RG, Shahid M, Zaagsma J, Nicholson CD. Human bronchial cyclic nucleotide phosphodiesterase isoenzymes: biochemical and pharmacological analysis using selective inhibitors. $\mathrm{Br} J$ Pharmacol. 1992;106(4):1028-1034. doi:10.1111/j.1476-5381.1992.tb14451.x

7. Page CP, Spina D. Phosphodiesterase inhibitors in the treatment of inflammatory diseases. In: Francis S, Conti M, Houslay M, editors. Phosphodiesterases as Drug Targets. Handbook of Experimental Pharmacology. Berlin: Springer; 2011:391-414.

8. Calverley PM, Rabe KF, Goehring UM, Kristiansen S, Fabbri LM, Martinez FJ. M2-124 and M2-125 Study Groups. Roflumilast in symptomatic chronic obstructive pulmonary disease: two randomised clinical trials. Lancet. 2009;374(9691):685-694. doi:10.1016/S01406736(09)61255-1

9. Singh D, Nandeuil MA, Pigeon-Francisco C, et al. Efficacy and safety of CHF6001, a novel inhaled PDE4 inhibitor in COPD: the Pioneer Dose Finding Study. Am J Respir Crit Care Med. 2019;199: A4529.

10. DALIRESP ${ }^{\circledR}$ (roflumilast) [prescribing information]. Wilmington. DE: AstraZeneca Pharmaceuticals LP; January, 2018.

11. Zuo H, Cattani-Cavalieri I, Musheshe N, Nikolaev V, Schmidt M. Phosphodiesterases as therapeutic targets for respiratory diseases. Pharmacol Ther. 2019;197:225-242. 
12. Singh D, Martinez FJ, Watz H, Bengtsson T, Maurer BT. A dose-ranging study of the inhaled dual phosphodiesterase 3 and 4 inhibitor ensifentrine in COPD. Respir Res. 2020;21(1):47. doi:10.1186/s12931-020-1307-4

13. Singh D, Abbott-Banner K, Bengtsson T, Newman K. The short-term bronchodilator effects of the dual PDE3 and PDE4 inhibitor RPL554 in COPD. Eur Respir J. 2018;52(5):1801074. doi:10.1183/ 13993003.01074-2018

14. Franciosi LG, Diamant Z, Banner KH, et al. Efficacy and safety of RPL554, a dual PDE3 and PDE4 inhibitor, in healthy volunteers and in patients with asthma or chronic obstructive pulmonary disease: findings from four clinical trials. Lancet Respir Med. 2013;1 (9):714-727. doi:10.1016/S2213-2600(13)70187-5
15. Pauwels RA, Buist AS, Calverley PM, et al. Global strategy for the diagnosis, management, and prevention of chronic obstructive pulmonary disease. NHLBI/WHO Global Initiative for Chronic Obstructive Lung Disease (GOLD) workshop summary. $\mathrm{Am}$ J Respir Crit Care Med. 2001;163(5):1256-1276. doi:10.1164/ ajrccm.163.5.2101039

16. Rennard SI, Calverley PM, Goehring UM, Bredenbröker D, Martinez FJ. Reduction of exacerbations by the PDE4 inhibitor roflumilast-the importance of defining different subsets of patients with COPD. Respir Res. 2011;12(1):18. doi:10.1186/1465-9921-1218

\section{Publish your work in this journal}

The International Journal of COPD is an international, peer-reviewed journal of therapeutics and pharmacology focusing on concise rapid reporting of clinical studies and reviews in COPD. Special focus is given to the pathophysiological processes underlying the disease, intervention programs, patient focused education, and self management protocols. This journal is indexed on PubMed Central, MedLine and CAS. The manuscript management system is completely online and includes a very quick and fair peer-review system, which is all easy to use. Visit http://www.dovepress.com/testimonials.php to read real quotes from published authors. 